\title{
Social Responsibility and Civic Readiness as Critical Higher Education Outcomes
}

\author{
Robert L. Caret ${ }^{1}$ \\ ${ }^{1}$ Office of the Chancellor, University System of Maryland \\ Cite as: Caret, R.L. (2019). Social Responsibility and Civic Readiness as Critical Higher Education Outcomes. \\ Metropolitan Universities, 30(4), 9-16. DOI: 10.18060/23551
}

This is an open access article distributed under the terms of the Creative Commons Attribution License.

Editor: Valerie L. Holton, Ph.D.

\section{The Work of Urban and Metropolitan Universities}

Throughout my 25 years in higher education leadership, overseeing two campuses and two university systems, I have maintained a strong connection to the Coalition of Urban and Metropolitan Universities (CUMU), both philosophically and in practical terms.

Early on in my tenure as president of San Jose State University, I established the overarching goal of making San Jose State the Metropolitan University of Silicon Valley. Complementing the institution's geographic location, size, and mission, all of which positioned it ideally for this role, I also saw a student population, a community role, and an ethos of service that spoke to the institution's responsibility as an urban citizen.

This same perspective was part and parcel of my approach at Towson University (TU). As president, I actively created a vision and an identity for the institution, focusing on its role as the Metropolitan University of Maryland. I established external partnerships with focuses on education, economic and workforce development, arts and culture, and social change.

As president of the 5-campus University of Massachusetts System (UMass) I oversaw two CUMU member institutions, UMass Lowell and UMass Boston. The University System of Maryland (USM), where I currently serve as chancellor, is itself a CUMU member, as are several of its component institutions, with Towson and the University of Maryland, Baltimore County (UMBC) "founding members" of CUMU as a formal organization. 
Throughout these years, I also had a very direct connection to CUMU, serving on several committees, on the Board of Directors, as a vice president, and, from 2006-2011, as CUMU president.

With this background, I know first-hand the distinctive perspective and unique tools that our comprehensive institutions can use to address social challenges and bring about meaningful change. In addition, I also recognize the special obligation our comprehensive metropolitan and urban universities have to be active and engaged in the communities they serve. These are the primary, 4-year, "access" institutions, not just in terms of the sheer numbers of students they educate, but also in terms of the composition of those students, serving as a vital higher education pathway for women, underrepresented minorities, and first-generation college students. Beyond that, our comprehensive universities stand as bridges, with numerous graduates going on to advanced degree programs at research universities.

\section{Social Responsibility}

Over the course of my entire career in higher education, spanning nearly fifty years as an educator, administrator, and leader, I have seen our society grow ever more complex and, unfortunately, divided. At the same time, as a society we have become increasingly unable to effectively navigate these differences and divisions in any sort of positive or productive manner.

From my perspective, the imperative of infusing, or perhaps reinfusing, an ethic of social responsibility across society at large is a duty higher education has not sufficiently prioritized in recent decades.

Given that our comprehensive universities are the higher education institutions most on the front lines of society, most representative of the diversity of our populace, and best equipped to engage directly and successfully with the community, this is a responsibility they must embrace.

And while metropolitan, urban, and comprehensive universities must lead this effort, all institutions of higher education, including public and private, 2-year and 4-year, research and comprehensive, must join in as well. We must pursue a broad-based strategy toward this unified goal.

The launching point for this effort requires us to stop thinking of higher education solely in terms of workforce development; our mission is much broader and should be recognized as such. I have long summarized my vision in higher education leadership in a single sentence: to graduate educated, enlightened citizens who are ready to go to work in all facets of life to make their lives, their communities, and our nation better. From a higher education perspective, this requires us to multi-task. 
In today's economy, skills and knowledge are the most valuable of commodities. This is especially true in Maryland, a leading STEM state, where the future is driven by innovation in the life sciences, cybersecurity, autonomous vehicles, and other areas. As such, I make no apologies for pursuing a strong economic development agenda as USM chancellor, and I have been expanding USM partnerships with the private sector from day one.

At the same time, however, we must always remember that the value of colleges and universities is far broader than simply educating people to qualify for jobs. Education for its own sake must always be central to our mission. Knowledge of history, an appreciation of art and literature, insight into philosophy, and an understanding of world cultures are indispensable aspects of a civilized society and the preservation of our American democracy.

We must consider the possibility that we have put such a premium on skills and workforce development, the secular side of higher education, that our broader mission of providing educated citizens, the spiritual side of higher education, is in danger of being lost. While this debate has been going on for decades, the intensity seems to have reached an all-time high.

Yes, we have an obligation to ensure that our graduates are prepared to meet the rigorous challenges of the new economy, armed with the knowledge and skills they need to compete. At the same time, we have an obligation to make sure our society is provided with the graduates it needs, graduates that have the education, the cultural and intellectual underpinnings, and the perspectives necessary to enable them to take their place as enlightened and progressive members and leaders of a democratic society.

To square this circle, we must mobilize the collective commitment and capacity of higher education to actively advance our communities through an embrace of the importance of civic readiness. To accomplish this, we need to reestablish higher education's critical leadership role in promoting "the we versus the me" through civic education, civic engagement, and civic responsibility.

\section{Civic Education}

We need a greater emphasis on civic education to ensure an informed, knowledgeable, and responsible citizenry that understands the origins, impact, importance, and fragility of democracy.

From a higher education perspective, impactful civic education means helping students develop a powerful civic skill set. They need to become thoughtful consumers of news and information, able to differentiate between fact and opinion, to see relationships and make connections, and to draw conclusions that are warranted from the data. This is almost a textbook definition of critical 
thinking. In addition, they need learning opportunities that shape their outlook and experiences to position them as informed, engaged members of their communities. And while they need to support freedom of expression and tolerance for different thoughts, they must also learn to temper that support with a commitment to a rigorous pursuit of fact and inquiry into truth.

This is a tall order, and it requires us to integrate civic education into core requirements across disciplines. As we all know, disciplinary specialization is a prominent feature of the modern American public university. Our faculty and students are more and more creatures of specialization. And while that has some positive aspects as far as repairing students for careers, it falls short in terms of educating the whole student.

While at Towson many years ago, I worked on a Senate effort to put in place a campus-wide understanding of what an arts and sciences based education is and why it is important. We wanted students to understand that our future was linked to our past and that the links between disciplines were important to the education we were providing and they needed. We reinforced the civic role of our graduates.

While I was president of the UMASS System, Massachusetts adopted a first-in-the-nation state policy on civic learning for public colleges and universities that incorporated civic learning as an expected outcome for undergraduate students. It is critical to note that this outcome was not just an understanding of the history and government of the United Sates and other nations. By calling for civic learning as a goal in campus strategic plans, we saw a statewide educational commitment to the intellectual elements of civic education, the practical aspects of civic engagement, and the values associated with democracy and with civic responsibility. It is not just a box we checked off after taking a course, it is a desire to ensure broad-based educational outcomes in our students.

In my current capacity as University System of Maryland chancellor, we are digging into this issue more deeply as well. Many of our campuses are fully engaged in Campus Compact. In addition, we updated our strategic plan, with perhaps the most significant change being the elevation of equity, diversity, inclusion, and civic engagement as a new, stand-alone goal. Most importantly, a few years ago the USM Board of Regents established a Civic Education Workgroup. The workgroup conducted a year-long inventory and assessment of campus-based activities and policies and developed systemwide initiatives to help our students graduate as more active and effective citizens. The USM now identifies civic literacy as a core expectation for all students and works to foster an ethos of civic engagement and participation across the system and its institution. 


\section{Civic Engagement}

A vital companion to civic education, civic engagement turns our needs and aspirations into actions. It strengthens connections to one another and inspires a commitment to work to make a difference in the life of our communities, the we versus the me. We need a two-pronged approach, first with the university itself active and engaged, and second with students (and faculty and staff) experiencing and internalizing public action and engagement.

One of the most active and articulate advocates for institutional involvement was a former USM colleague David Adamany, former president of Wayne State. He provided an example of this philosophical approach of institutional engagement: his vision for universities as anchor institutions, particularly in urban environments, drove his concept of "the University as Urban Citizen." Adamany envisioned urban universities held to the highest standards of civic commitment, while at the same time carrying out their traditional roles of asking questions, seeking knowledge, teaching, and research. He saw no inherent inconsistency between these traditional functions and urban citizenship. His 15 years leading Wayne State were marked by expansive partnerships with the K-12 community, business leaders, public safety officials, state and local elected leaders, and others, all to advance his goal of a national research university with an urban teaching and service mission. This concept that higher education institutions must not simply be in communities, but rather part of communities must be our standard.

It is, however, important to differentiate between actions that are little more than volunteerism or service learning and genuine civic engagement. This is not to denigrate any efforts that target critical social needs. If anything, we could use much, much more active and personal engagement in communities. What I am referring to is civic engagement that requires students to come to terms with their individual duty as citizens, to become active participants in democracy itself, to understand the work of citizenship, to understand that citizenship is more than rights; it is also responsibilities. Connecting teaching, research, and service to community engagement will more effectively yield civically engaged students, scholars, and institutions.

Issued every five years, the Carnegie Community Engagement Classification, now affiliated with the Swearer Center for Public Service at Brown University, is perhaps the most significant identifier of true community engagement across higher education. The classification acknowledges colleges and universities with an institutional focus on collaboration with their broader communities in efforts that enrich scholarship, research and creative activity; prepare educated, engaged citizens; strengthen democratic values and civic responsibility; address critical societal issues; and contribute to the public good.

In recognition of the value of this designation and, more importantly, the growing importance of the concept of true civic engagement that it represents, the USM made a concerted, coordinated 
effort to bring Carnegie Community Engagement Classification to more of our campuses. For the 2015 Community Engagement Classification cycle, Towson University was the only USM instruction represented among the 240 colleges and universities recognized. Other campuses have initiated the process and will apply at the next open application cycle.

There are other, more targeted effort that support this agenda as well. For example, The Voter Friendly Campus designation program seeks to support and acknowledge campusbased efforts that help students overcome barriers to participating in the political process as well as efforts that develop a culture of democratic engagement on campus. In addition, as the 2020 census approaches, colleges and universities, including those in Maryland, are gearing up to engage students, staff, faculty, administrators, and community partners to ensure a fair and complete count in the 2020 Census. Given that voting and the decennial census represent foundational cornerstones of democracy, it would be nothing short of a dereliction of duty for a college or university, especially a public, metropolitan university, to pass up the opportunity to engage students, faculty, staff, and the surrounding communities in support of full participation.

\section{Civic Responsibility}

The third leg of the stool supporting democracy is civic responsibility, an idea first recorded by the ancient Romans and embedded in our Constitution, that directly acknowledges our obligation to make contributions for the good of the whole society.

If we consider a campus as its own society, its own democratic society, what do we want to see? We want to see a learning environment that features open, reasonable, respectful discussion of political, social, and other issues. We want to see the student/faculty relationship evolve to one where faculty do not simply serve as objective experts, but rather as intellectuals who catalyze debate and forge relationships among diverse constituencies, and we want to see students with a more active role in campus decision-making. In such an environment, students, regardless of major, will graduate with the intellect, skills, experience, and perspective they need to be active and engaged citizens.

The notion that an educated citizenry is vital for our survival as a free people, and the imperative mission of higher education to educate for democracy, was recognized from the earliest days of our nation and supported by our founders.

I would contend that civic responsibility would essentially become an automatic outcome if we embraced enhancing civic education and provided opportunities for civic engagement as a truly institution-wide or system-wide priority. 
In Maryland, this ethic of civic responsibility is manifesting itself through our significant, system wide re-commitment to the City of Baltimore by the USM and its institutions. Five of our 12 universities call greater Baltimore home. A few years ago, we moved the system headquarters from suburban Washington to downtown Baltimore to better focus on the city's needs. Additionally, we established Baltimore Power, or B-Power, a new partnership to better leverage USM resources to improve educational outcomes for Baltimore City students. In partnership with Baltimore City public schools and Baltimore City Community College, B-Power uses both college readiness programs and dual enrollment courses, exclusively targeting foundational English and mathematics classes. Through B-Power, USM is creating a new Baltimore-centric pathway from high school, to a two-year community college degree, to a four-year degree at a USM (or non-USM) institution.

Our goal with B-Power is ambitious; we hope to dramatically improve the rates of high school graduation, college going, and degree attainment for students throughout Baltimore. We are building a much wider alliance with other USM institutions, non-profits, businesses, schools, and education advocacy organizations working together. Baltimore is the state's largest city and a vital economic engine; it must have a future of educational and economic opportunity. A focus on college and career readiness for city students is an imperative. B-Power is a key part of a bringing about a brighter future for city students, the city, the region, and the state.

\section{Presidential Leadership: The Tie That Binds}

For higher education to meet these obligations, to effectively weave civic education, civic engagement, and civic responsibility into the very fabric of who we are and what we do, will require significant change; changes in policy, changes in behavior, changes in resource allocation, and more. In addition, there is the difficult prospect of overcoming institutional inertia and, in some cases, flat-out resistance to this change. Factor in the need to invest in in highquality faculty development that enables faculty and students to engage in civil discourse, and the magnitude of the task becomes clearer.

Without doubt, broad institutional support and commitment will be required. Bringing about this level of commitment and support will be driven by presidential leadership. Leaders of institutions of higher education must not shy away from these challenges. This is, in fact, where leadership matters most. It will not be easy, but it is essential. The fact that so many aspects of our civic life have become dysfunctional makes this effort all the more important and imperative. If we are committed, it can be our efforts that help move us from civic dysfunction to civic enlightenment. 


\section{Note}

Chancellor Caret's piece is largely adapted from an address he gave at the American Association of State Colleges and Universities (AASCU) Annual Meeting in Fall 2017. 